\title{
Towns, Gowns, and Gloves: The Status of Infection Control in Community Hospitals
}

\author{
August J. Valenti, MD, FACP
}

On February 10, six hundred fifty-one years ago, a group of Oxford scholars vociferously objected to the wine they were served at the Swindlestock Tavern. A student launched a flagon at the wine merchant, roiling existing tensions between the university and townies. Three days of deadly rioting ensued. ${ }^{1}$ Today, contentious relations between academic medical centers and community hospitals may seem as pointless as the St. Scholastica Day riots, but, although encouraging signs of increasing collaboration among healthcare factions exist, a growing public edginess over hospital-acquired infections is developing into a town-and-gown controversy. The rhetoric surrounding this issue in California, Pennsylvania, and elsewhere in recent years is enough to prompt the innocent observer to watch for flying quart pots.

No hospital in the United States, regardless of its size, resources, or location, can ignore the patient-safety movement, which properly views hospital-acquired infections as preventable adverse events. Many state legislatures are under pressure from various groups to enact laws requiring hospitals to disclose "infection rates." In 2004, the Society for Healthcare Epidemiology of America's board made the process of public reporting-which is too often driven by impatience and, in some instances, disconnected from sound epidemiologic principles-a priority. ${ }^{2}$ Likewise, accrediting bodies have introduced more infection and infection prevention measures into their indicators of quality. Although this intensified scrutiny of nosocomial infections is likely to increase the burden on infection control departments, especially in smaller hospitals, it might lead to a greater appreciation for the role of hospital epidemiology and infection prevention in all healthcare facilities, regardless of size or affiliation.

This issue of the journal offers a number of articles that examine some important challenges facing infection control today from the perspective of the community hospital. I will comment on 4 of them here. Of note, 2 of these studies were conducted within small healthcare systems and one within a large healthcare alliance. Regional infection control consortia give small hospitals the opportunity to share valuable resources and expertise with larger neighbors and, as these articles demonstrate, provide arable ground for scientific study. These studies look at how infection control efforts are configured in community hospitals and how these hospitals are dealing with the challenges of resource availability, control of drug-resistant organisms, and antibiotic stewardship. Each of these articles is sure to be of particular interest to readers working in community-based institutions, but they should also stimulate academicians to consider how they might support their colleagues who are striving to bring evidence-based practices, which result from scientific studies, to the community.

Though small, the study by Christenson et al. ${ }^{3}$ of VHA hospitals in various regions of the country provides insight into the state of infection control in community hospitals. The authors surveyed 31 hospitals ranging in size from fewer than 50 beds to more than 500 beds to assess the staffing, structure, and functions of infection control departments in participating facilities. In addition to the demographic survey, participants were asked to submit data for an observational study of compliance with infection control guidelines. The study used process measures of interest to key accreditation bodies: hand hygiene practices, rates of ventilator-associated pneumonia, catheter-related bloodstream infection, and catheter-related urinary tract infection.

A third of the hospitals surveyed had levels of infection control staffing below the level of 1 infection control professional per 100 occupied beds, and only 1 hospital reported data support within the infection control department. ${ }^{4}$ It is encouraging that some hospitals felt their infection control program was supported by their administrations and medical directors, but lack of physician support underscored the need to identify and correct the reasons for this resistance. The observational study revealed inconsistencies in infection control practices, as well as in compliance with evidence-based recommendations for reducing specific healthcare-associated infections among participants. This is well analyzed and discussed by Christenson et al. ${ }^{3}$ One hopes that larger studies of this type will appear in the future.

\footnotetext{
Dr. Valenti is from Epidemiology and Infection Prevention, Maine Medical Center, Portland, Maine.

Received January 24, 2006; accepted February 10, 2006; electronically published March 6, 2006.

Infect Control Hosp Epidemiol 2006; 27:225-227

(C) 2006 by The Society for Healthcare Epidemiology of America. All rights reserved. 0899-823X/2006/2703-0001\$15.00.
} 
The article by Kaye and colleagues, ${ }^{5}$ describing results from the first 3 years of operation of the Duke Infection Control Outreach Network, calls to mind the work of Ostrowsky et al. ${ }^{6}$ in the Siouxland region of Iowa, Nebraska, and South Dakota. Ostrowsky's group rigorously applied Centers for Disease Control and Prevention guidelines across 32 healthcare facilities and reported dramatic reductions in the number of vancomycin-resistant Enterococcus infections among participants. The Duke-affiliated team standardized surveillance methods, provided frequent feedback, and applied Centers for Disease Control and Prevention guidelines at 12 hospitals in North Carolina to achieve reductions in the numbers of bloodstream infections, nosocomial infections with methicillin-resistant Staphylococcus aureus (MRSA), ventilatorassociated pneumonia, and employee exposures to bloodborne pathogens. Kaye et al..$^{5}$ estimated that there were remarkable economic benefits; and although cost-sparing analyses (Kaye and colleagues used attributable cost and mortality data from published studies) are open to question, they can help make the business case for infection control. The Duke Infection Control Outreach Network is in its infancy, and we expect that future work will address actual measures of compliance, the effect of improved case-finding, and the question of which interventions drive reductions in the number of infections. Nonetheless, this article, along with the high-profile successes of infection control consortia such as the Barnes-Jewish Hospital Infection Control and Healthcare Epidemiology Consortium in the St. Louis area, will hopefully encourage others to consider the advantages of regional collaborations. ${ }^{7}$

The admirable analysis by West et al. ${ }^{8}$ adds to the sizeable body of evidence supporting the effectiveness of the 2003 Society for Healthcare Epidemiology of America guidelines for preventing nosocomial transmission of MRSA and vancomycin-resistant Enterococcus. ${ }^{9}$ Not surprisingly, West et al. ${ }^{8}$ found that surveillance to identify patients at risk for MRSA colonization, performance of screening cultures for these patients, and use of contact precautions for colonized patients were effective, cost-sparing measures for decreasing nosocomial transmission of MRSA. Notably, patients infected with MRSA had been placed in isolation since 1988, but infection rates remained stable, despite the additional measure of screening nares specimens from patients in the intensive care unit, a practice initiated in 2001. It was only after surveillance targeted high-risk patients throughout the hospital that a significant reduction in infection rates was achieved. West et al. ${ }^{8}$ identify barriers to effective control of MRSA infection in a community hospital system, but the cultural changes resulting from heightened efforts to control MRSA infection in this system should encourage broader application of the Society for Healthcare Epidemiology of America recommendations.

The favorable impact of antimicrobial stewardship on antibiotic use, on healthcare expenditures, and, to a lesser extent, on bacterial resistance has been demonstrated in a number of studies in large as well as small hospitals. ${ }^{10}$ The proportional influence of infection control practices, compared with antibiotic optimization practices, on reduction of resistance seems to depend on the organism and the mode of transmission: horizontally transmitted resistant organisms, such as MRSA, are more amenable to infection control interventions, whereas resistant organisms arising from the endogenous flora of patients undergoing antibiotic therapy may be more influenced by antibiotic stewardship interventions. ${ }^{11}$ Vancomycin-resistant Enterococcus may fall somewhere in between.

Philmon et al. ${ }^{12}$ targeted use of intravenous-to-oral conversion of antibiotic therapy, use of antimicrobial prophylaxis for clean and clean-contaminated procedures, and use of antibiotics that are associated with high cost, high risk, or increased resistance or are treatments of "last resort." They used a concurrent review approach, restricting the use of certain agents and requiring infectious disease consultation for continuing therapy with other agents. Their analysis compared defined daily dose data from 1 year before through 3 years after the start of the program.

Although there were cost benefits, the impact on bacterial resistance was not as conclusive. Except for Klebsiella species, most of the gram-negative organisms they tested showed no significant change in susceptibility to ceftazidime or cefepime, 2 of the restricted antibiotics. Philmon et al. ${ }^{12}$ do not indicate whether they tested for extended-spectrum $\beta$-lactamase-producing organisms in their institution. This would be of interest in future studies, in light of work by Lautenbach et al. ${ }^{13}$ and others that suggests cumulative antibiotic exposure is the only independent predictor of infection with these organisms. In my institution (Maine Medical Center, Portland, $\mathrm{ME}$ ), we use computer-assisted decision support to discourage the use of ceftazidime and use cefepime as our workhorse cephalosporin because of the evidence that fourth-generation cephalosporins are less susceptible to AmpC $\beta$-lactamases and may actually be better for "hospital ecology." ${ }^{14-16}$ To be sure, antimicrobial stewardship and infection control programs must be closely allied.

Despite its historical primacy among hospital interventional and quality-of-care initiatives-and its proven efficacy-the infection control program of today struggles to live up to its high standards in a cost-cutting environment, and it often finds itself competing with other quality-of-care initiatives for funding. This is an unfortunate distraction for already beleaguered infection control professionals who, in addition to their traditional duties of surveillance, education, and outbreak management, now have the challenges of emerging antimicrobial resistance, public reporting, a potential pandemic of influenza, possible biological terrorism, and vaccine shortages on their plates. Moreover, hospitals can view scientifically supported recommendations as too costly to implement. Community hospitals, particularly rural facilities, may be unable to attract professionals with infection control expertise, and, where epidemiologists and infection control professionals are available, administrators may be unable or unwilling to provide sufficient support for them to devote adequate time to traditional re- 
sponsibilities, let alone investigate process breakdowns and bring about the cultural changes that are needed to implement evidence-based practices.

If infection control professionals are to be seen as important and necessary patient-safety advocates, they must convince a wider audience of the validity and utility of their methods. Creative solutions to the effects of cost cutting or inadequate support, such as sharing resources in a healthcare network, can lead to enhanced results in identifying regional problems, implementing best practices, evaluating outcomes, and realizing cost savings for participating institutions. ${ }^{17}$ Those who manage the financial resources of community hospitals should have an appreciation for the evolution, methodology, and efficacy of infection control programs. For their part, infection control professionals must be able and willing to discuss the impact of their recommendations on the resources of their facilities. Educational outreach, at both the local and national levels, must include the public.

A highly regarded mentor of mine once assured me that physicians leaving academia could practice academic medicine in the community as easily as an academic physician could behave like a community physician in academia (presumably, he had an ineducable lout in his mind's eye). He recently reconsidered the ease with which the former could be accomplished, given the current milieu in which we practice. This issue of the journal should encourage communitybased infection control professionals to persist in their efforts to translate science into practice. Now, let us don our gowns, move carefully about our towns... and resist the temptation to toss our flagons.

Address reprint requests to August J. Valenti, MD, Epidemiology and Infection Prevention, Maine Medical Center, 22 Bramhall St., Portland, ME 04102-3134 (valena@mmc.org).

\section{REFERENCES}

1. Oxford Inscriptions Web site. Available at: http://www.oxfordinscriptions .com/oxford_university.htm. Accessed February 16, 2006.

2. Wong ES, Rupp ME, Mermel L, et al. Public disclosure of healthcareassociated infections: the role of the Society for Healthcare Epidemiology of America. Infect Control Hosp Epidemiol 2005; 26:210-212.
3. Christenson M, Hitt JA, Abbott G, Septimus EJ, Iversen N. Improving patient safety: resource availability and application for reducing the incidence of healthcare-associated infection. Infect Control Hosp Epidemiol 2006; 27:245-251 (in this issue).

4. O'Boyle CA, Jackson M, Henley SJ. Staffing requirements for infection control programs in US healthcare facilities: Delphi Project. Am J Infect Control 2002; 30:321-333.

5. Kaye KS, Engemann JJ, Fulmer EM, Clark CC, Noga EM, Sexton DJ. Favorable impact of an infection control network on nosocomial infection rates in community hospitals. Infect Control Hosp Epidemiol 2006; 27:228-232 (in this issue).

6. Ostrowsky BE, Trick WE, Sohn AH, et al. Control of vancomycin-resistant enterococcus in health care facilities in a region. $N$ Engl J Med 2001; 344:1427-1433.

7. Murphy DM. From expert data collectors to interventionists: changing the focus for infection control professionals. Am J Infect Control 2002; 30:120-132.

8. Muto CA, Jernigan JA, Ostrowsky BE, et al. SHEA guideline for preventing nosocomial transmission of multidrug-resistant strains of Staphylococcus aureus and Enterococcus. Infect Control Hosp Epidemiol 2003; 24:362-386.

9. West TE, Guerry RN, Hiott M, Morrow N, Ward K, Salgado CD. The effect of targeted surveillance for control of methicillin-resistant Staphylococcus aureus in a community hospital system. Infect Control Hosp Epidemiol 2006; 27:233-238 (in this issue).

10. Fraser G, Stogsdill P, Owens RC. Antimicrobial stewardship initiatives: a programmatic approach to optimizing antimicrobial use. In: Owens RC, Ambrose PG, Nightingale CH, eds. Antibiotic Optimization: Concepts and Strategies in Clinical Practice. New York, NY: Marcel Dekker; 2005: 261-326.

11. Rice LB. Controlling antibiotic resistance in the ICU: different bacteria, different strategies. Cleve Clin J Med 2003; 70:793-800.

12. Philmon C, Smith T, Goodman E. Controlling antimicrobial use in a community teaching hospital. Infect Control Hosp Epidemiol 2006; 27: 239-244 (in this issue).

13. Lautenbach E, Patel JB, Bilker WM, Edelstein PH, Fishman NO. Extended-spectrum $\beta$-lactamase-producing Escherichia coli and Klebsiella pneumoniae: risk factors for infection and impact of resistance on outcomes. Clin Infect Dis 2001; 32:1162-1171.

14. Kollef MH. The clinical impact of scheduled antibiotic class changes for the empiric treatment of nosocomial gram-negative bacterial infections in the intensive care unit setting. In: Program and abstracts of the 39th Interscience Conference on Antimicrobial Agents and Chemotherapy, San Francisco, Sept 26-29, 1999. Abstract 701.

15. Owens RC Jr, Ambrose PG, Quintiliani R. Ceftazidime to cefepime formulary switch: pharmacodynamic and pharmacoeconomic rationale. Conn Med 1997; 61:225-227.

16. Bantar C, Sartori B, Vesco E, Heft C, Saul M, Salamone F, Oliva ME. A hospitalwide intervention program to optimize the quality of antibiotic use: impact on prescribing practice, antibiotic consumption, cost savings, and bacterial resistance. Clin Infect Dis 2003; 37:180-186. 